\title{
A capacidade civil contratual da pessoa com deficiência no Estatuto da Pessoa com Deficiência sob a perspectiva da análise econômica do direito
}

\author{
The contractual civil capacity of the person with disability in the Statute on the \\ Person with Disability from the perspective of the economic analysis of law
}

\author{
Oksandro Osdival Gonçalves* \\ Anelize Pantaleão Puccini Caminha*
}

\section{Resumo}

O artigo visa enfrentar o tema da capacidade civil contratual da pessoa com deficiência, á luz do Estatuto da Pessoa com Deficiência, aplicando, para tanto, o instrumental da Análise Econômica do Direito. O método empregado foi o hipotéticodedutivo, com ampla revisão bibliográfica, tendo como principal objetivo promover uma análise crítica do novo regime das capacidades que impactou o Código Civil brasileiro. O trabalho procura demonstrar que o sistema de garantias outrora existente foi superado, o que, de um lado, trouxe para o plano da igualdade formal as pessoas com deficiência, mas de outro pode ter causado um problema ao ampliar o horizonte para a igualdade material no plano contratual, devido o desuso do antigo sistema de proteção. Assim, a doutrina e a jurisprudência encontrarão novos desafios para analisar o regime das capacidades, em especial quando esta é manifestada na forma de contratos, auxiliando pessoas com deficiência especialmente aquelas de natureza cognitiva - e evitando que suas vontades sejam prejudicadas ou que venham a assumir um contrato viciado. A partir disso, portanto, o artigo utiliza o instrumental da Análise Econômica do Direito, a partir da racionalidade limitada e da assimetria informacional para, ao final, sustentar que, embora o regime dos contratos para as pessoas com deficiência tenha sido alterado, é preciso conferir a essas pessoas com deficiência uma proteção oriunda da sua hipervulnerabilidade. E por fim o presente artigo reconhece que o sistema atual elevou os custos de transação associados ao contrato e, em razão disso, os custos deverão ser apurados no regime ex post.

Palavras-chave: Estatuto da pessoa com deficiência. Políticas públicas. Desenvolvimento econômico e social. Análise econômica do direito.

\section{Abstract}

The article aims to confront the issue of the contractual civil capacity of persons with disabilities, in light of the Statute on Persons with Disabilities, applying, for this purpose, the instrument of economic analysis of the law. The method used was hypothetical deductive, with extensive literature review, with the principal objective of promoting a critical analysis of the new regime of capabilities that impacted the Brazilian Civil Code. The paper purses to demonstrate that the formerly existing guarantee system has been succeeded, which on the one hand has brought people with disabilities to formal equality, but on the other may have caused a problem by widening the horizon for material equality in the contractual plan because that protection system has ceased to exist. Consequently, doctrine and jurisprudence will find new challenges in analyzing the regime of capacities, especially when manifested in the form of contracts by persons with disabilities, especially those who have a cognitive disability, who may have a serious disrespect for the desire and an abusing agreement. Instead of this reason, the article used the instrument of economic analysis of law, based on limited rationality and informational asymmetry, in the end, to maintain that, although the regime of contracts for persons with disabilities has changed, it is necessary to give them a due to its hyper vulnerability, and that the current system has increased the transaction costs associated with the contract as it will require that the expenses be calculated on an ex-post basis.

Keywords: Statute on Person with Disability. Public Policy. Economic and Social Development. Economic Analysis of Law.

Doutor em Direito Comercial pela Pontifícia Universidade Católica de São Paulo - PUC/SP. Mestre em Direito Econômico pela Pontifícia Universidade Católica do Paraná - PUC/PR. Advogado. Professor do Programa de Pós-Graduação em Direito (Mestrado/Doutorado), de Direito Comercial. Direito Empresarial do Curso de Especialização em Direito Civil e Empresarial da Escola de Direito da Pontifícia Universidade Católica do Paraná - PUC/PR. Membro do Conselho Editorial da Editora Fórum. Coordenador da Revista de Direito Empresarial. Bolsista CAPES processo n. BEX 049016-4. CAPES Foundation, Ministry of Education of Brazil, Brasília/DF 70040-020, Brazil. E-mail: oksandro@ oksandro.adv.br

Doutoranda em Direito pela Pontifícia Universidade Católica do Paraná - PUC/PR. Mestre em Direito Civil e Empresarial com ênfase em Direito e Especialista em Processo Civil pela Universidade Federal do Rio Grande do Sul - UFRS. Graduada em Direito pela Pontifícia Universidade Católica do Rio Grande do Sul - PUC/SP. Advogada. E-mail: anelize@caminhaadvogados.com.br 


\section{Introdução}

Com o propósito de promover a efetiva integração social da pessoa com deficiência, antes limitada a aspectos educacionais e de reabilitação profissional, o legislador incorporou ao ordenamento jurídico pátrio as diretrizes da Convenção Internacional da Pessoa com Deficiência (CIPD), dentre as quais merece destaque o reconhecimento de sua capacidade civil.

Para produzir efeitos jurídicos - permitindo a aquisição, a modificação ou a extinção de direitos e obrigações -, o contrato deve preencher certos requisitos de ordem geral e especial - inclusive de natureza subjetiva -, sob pena de invalidação e, consequentemente, frustração da operação econômica engendrada pelos contratantes.

Nesse contexto encontra-se a importância do estudo das alterações promovidas pela Lei $n^{\circ} 13.146$, de de 2015 - o Estatuto da Pessoa com Deficiência (EPD) - no Código Civil brasileiro. Como as inovações legislativas implementadas a partir de 2015 têm repercussão na Teoria Econômica dos Contratos, em especial no plano de validade, faz-se necessário que a capacidade civil contratual da pessoa com deficiência precise, então, ser reanalisada após a edição do Estatuto da Pessoa com Deficiência (EPD). Propõe-se, na presente pesquisa, que essa nova abordagem ocorra através do instrumental da Análise Econômica do Direito (AED).

Para desenvolvê-la, na primeira parte, aborda-se a capacidade civil como requisito geral de validade do contrato e as peculiaridades relativas à pessoa contratante com deficiência. Na segunda parte, examina-se a validade dos contratos celebrados por pessoas com deficiência em uma perspectiva econômica, discorrendo sobre sua autonomia para o ato de contratar e as consequências econômicas da invalidação de ajustes por elas firmados. Sem o intuito de esgotar o tema, propõe-se uma reflexão sobre o impacto econômico do novo quadro de nulidades dos contratos celebrados por pessoa com deficiência, com o propósito de realçar a necessidade de as decisões judiciais ponderarem, entre outros aspectos, sobre os critérios econômicos de custo e benefícios sociais na solução desses litígios.

A partir disso, a metodologia utilizada no presente artigo tem-se como hipotético-dedutiva, visando a análise dos erros da hipótese inicial de pesquisa com a análise teórica doutrinária, através de uma análise imbricada entre o direito civil e a Análise Econômica do Direito. Tal metodologia, portanto, pretende demonstrar a possibilidade de se tornar ainda mais eficiente o processo de desenvolvimento das capacidades das pessoas com deficiência, o que implica maior eficiência dos direitos fundamentais. Dessa forma, a escolha do método se dá pela necessidade de observar o impacto das nulidades dos contratos com a alteração realizada no campo, principalmente, na validade dos negócios jurídicos pelo EPD, que introduziu novos mecanismos no Código Civil brasileiro e assegurou a plena capacidade da pessoa com deficiência como regra geral.

\section{A capacidade civil como requisito de validade dos contratos em geral}

Como decorrência de capacidade de direito, a personalidade jurídica consiste na aptidão, ínsita a qualquer ser humano, para ser sujeito ou titular de direitos (pretensões, ações e exceções) e obrigações, e de exercer atos da vida civil (MONTEIRO, 1974). Nesse aspecto, diferencia-se da capacidade de exercício ou de fato, que corresponde ao poder de exercer, pessoalmente, direitos e contrair obrigações vinculadas a determinados fatores objetivos, como: idade e estado de saúde ${ }^{1}$. Por esse motivo a incapacidade para os atos da vida civil é sempre de exercício, jamais de direito.

No campo contratual, a legislação civil elenca, como requisitos subjetivos de existência e validade do ajuste, (i) a manifestação de duas ou mais vontades e a capacidade genérica dos contratantes, (ii) a aptidão específica para contratar e (iii) o consentimento.

A capacidade genérica dos contratantes é elemento subjetivo de ordem geral, de tal modo que o contrato pode ser nulo ou anulável. Portanto, em caso de incapacidade, absoluta ou relativa, ela deve ser suprida por representação ou assistência - Arts. 1.634, inciso VII, 1.747, inciso I, e 1.781, todos do Código Civil (CC). A capacidade específica para contratar deve existir no momento da manifestação de vontade do contratante, e é exigida em determinados negócios jurídicos, como a doação, ou seja, somente pode doar quem detiver o poder de disposição da coisa ou direito que é objeto do contrato.

Miranda (1983, p. 157) refere-se à existência de capacidade de direito e capacidade de obrar, abrangendo a capacidade de praticar atos-fatos jurídicos e atos jurídicos em sentido estrito, de manifestar vontade em negócios jurídicos e praticar atos ilícitos. 
O passo seguinte para se chegar ao ponto nodal do presente artigo é tratar do consentimento como requisito inerente aos contratos, pois este deve ser - além de livre e espontâneo - recíproco e abrangente do consenso em torno da existência e natureza do contrato, do objeto do contrato e das cláusulas que o compõem.

Sob a ótica econômica, o objetivo principal do contrato é permitir que as partes obtenham vantagens recíprocas, na forma do que se denomina "Ótimo de Pareto", para os que devem ter liberdade para decidir se querem contratar, escolher a parte contratante e determinar o conteúdo das cláusulas que Ihes convenha (MACKAAY, ROUSSEAU, 2015, p. 406)². Entretanto, o exercício dessa liberdade, de autorregramento, pressupõe a existência de uma capacidade civil plena antecedente.

Neste ponto, a virada corpernicana experimentada pelo legislador pátrio ocorreu ao recepcionar em nosso ordenamento jurídico constitucional - com status de emenda constitucional -, a CIPD, deu origem à Lei $n^{\circ} 13.146 / 2015$, também conhecida como EPD. ${ }^{3}$ A partir da sua entrada em vigor, alteram-se substancialmente os Artigos $3^{\circ}$ e $4^{\circ}$, do Código Civil, e deixa de existir a figura da incapacidade absoluta. No âmbito da incapacidade relativa, a proteção passa a incidir em favor daquela pessoa que, por causa transitória ou permanente, não possa exprimir sua vontade. Assim, a pessoa com deficiência passa a ter o direito ao exercício de sua capacidade legal em igualdade de condições com as demais pessoas, ou seja, as regras de anulabilidade e nulidade passam a ser uniformes sem qualquer distinção.

Assim, o impacto dessa mudança é substancial, pois se estima que no Brasil aproximadamente $25 \%$ (vinte e cinco por cento) da população tenha algum tipo de deficiência, seja ela física ou cognitiva (BRASIL, 2012, p. 6)4, ou seja, um número substancial de pessoas que precisa de uma tutela adequada para os seus direitos. A partir disso, portanto, para os fins deste artigo, interessa-nos a deficiência cognitiva que pode, de alguma forma, afetar o processo decisório que leva à celebração do contrato.

Portanto, o direito contratual sofre uma grande mudança a partir da entrada em vigor do Estatuto da Pessoa com Deficiência (EPD), na medida em que a doutrina tradicional construída em torno da capacidade para celebrar contratos precisa ser adaptada à premissa de que, em regra, o contrato celebrado por pessoa com deficiência cognitiva é válido e produz efeitos, para o bem e para o mal.

O sistema protetivo que vigorava antes do EPD, ainda que se possa criticá-lo por, de certa forma, funcionar como um meio de exclusão social, tinha uma razão de ser em função justamente dos possíveis vícios de consentimento que poderiam vir a existir caso uma pessoa com deficiência cognitiva expressasse a sua vontade no sentido contratual do termo. É bem verdade que neste ponto é preciso fazer um recorte, pois existem vários níveis e gamas de deficiências cognitivas que precisam ser avaliadas, desde aquelas que suprimem substancialmente a validade do elemento volitivo, até aquelas que sequer permitem ser possível aferir de pronto qualquer problema no momento da manifestação da sua vontade.

O legislador, por um lado, optou por suprimir a segregação social da pessoa com deficiência que resultava em perda não só para o indivíduo - que vê cerceado seu desenvolvimento pessoal -, como também para a sociedade que não tem a oportunidade e a possibilidade de apreender, em toda sua potencialidade, uma parcela significava de seus membros. Todavia, por outro lado, o legislador também assumiu o risco associado à supressão das regras anteriores, que evitavam que pessoas com deficiência ficassem mais suscetíveis aos problemas derivados da celebração de contratos em um regime de paridade cognitiva presumida. ${ }^{5}$

2 A respeito disso Araújo (2014) destaca a questão da eficiência como um critério de aferição para os contratos, partindo-se da maximização do bem-estar pelos resultados. Ainda, ensina que a situação de eficiência de Pareto é alcançada quando é encontrado o grau máximo de bem-estar total agregado, de somatório de todos os excedentes dos consumidores e de todos os excedentes dos produtores, momento em que não seria possivel aumentar o bem-estar de alguém sem se sacrificar o bem-estar de outrem.

3 Em 2007, o Brasil assinou a Convenção Internacional sobre os Direitos das Pessoas com Deficiência e seu Protocolo Facultativo, a qual foi aprovada pelo Congresso Nacional, sob o rito especial previsto no Artigo $5^{\circ}$, $§ 3^{\circ}$, da Constituição Federal (Decreto Legislativo n. ${ }^{\circ} 186$, de 9 de julho de 2008 , e Decreto $n .^{\circ} 6.949$, de 25 de agosto de 2009), sendo incorporada ao ordenamento jurídico, com status equivalente a emenda constitucional.

4 Nos termos da Nota Técnica 01/2018 do Instituto Brasileiro de Geografia e Estatística (IBGE), o percentual de $25 \%$ foi modificado a partir da mudança de critério para definir quem se enquadra no conceito de deficiência. Para possibilitar a comparabilidade com outros Estados, foram considerados os critérios internacionais definidos pela Organização das Nações Unidas (ONU) e Organização Mundial da Saúde (OMS), aplicando-se o critério do Grupo de Washington, de tal sorte que a reinterpretação dos dados anteriores aponta para um percentual de $6,7 \%$ e não mais de $25 \%$ do total de brasileiros com alguma deficiência. Assim, ao que parece, adota-se um critério mais biométrico do que a perspectiva social adotada pelo Censo do IBGE em seu questionário (IBGE, 2018, p. 1-8)

5 Neste mesmo sentido, advoga-se a tese de que o benefício oriundo do EPD também pode levar a riscos às pessoas com deficiência, em razão do aumento do grau de proteção em relação a certos atos da vida civil. Sobre o tema compreende-se que: "Se por um lado, a alteração realizada pela Lei $n^{\circ} 13.146$ de 2015 no Código Civil Brasileiro ocasionou um largo passo em relação à dignidade da pessoa humana, por outro, impossibilitar que uma pessoa com sérios transtornos mentais possa ser absolutamente incapaz também pode gerar sérios riscos, uma vez que estas pessoas estariam desprotegidas de certos atos para os quais elas não têm condições de avaliar sem auxílio." (SALGADO, 2017, p. 303-320). 
Com efeito, se antes a presunção era em favor da pessoa com deficiência, pela legislação em vigor essa presunção simplesmente não pode mais ser invocada, senão em situações em que a vontade tenha sido efetivamente manipulada justamente no ponto da compreensão cognitiva, ou seja, se o exercício da capacidade legal deve ser feito em igualdade de condições com as demais pessoas, essa premissa orienta toda a formação do contrato e somente poderá ser mitigada à luz de equiparações especialíssimas.

Disso decorre a necessidade da interação entre Direito e Economia, pois o fenômeno jurídico compreende a experiência desenvolvida pela razão e sofre a influência das mudanças sociais e econômicas concretas (FARIA, 1994), impactando sobre o processo decisório dos indivíduos. O modelo de capacidade atualmente em vigor parte do pressuposto da igualdade formal e material, ao estabelecer que o exercício da capacidade legal se dá em igualdade de condições com as demais pessoas, não sendo lícito invocar, ao menos a priori, uma deficiência cognitiva que não tenha sido previamente demarcada junto ao outro contratante (sem deficiência), presumindose válida a contratação até que se prove que houve algum vício capaz de macular o consentimento que levou à formação do contrato.

Novamente o problema é de grande dimensão, pois essa verificação deverá partir, à luz de uma interpretação sistêmica, do mesmo padrão exigido para as pessoas com plena capacidade intelectual (Art. 84, do EPD), e a partir da definição desse padrão deslocar-se para averiguar se a deficiência cognitiva era efetivamente capaz de alterar o processo decisório que levou à formação do vínculo.

De um lado é certo que a compreensão das peculiaridades da realidade das pessoas com deficiência permitirá ao operador do Direito oferecer soluções adequadas aos problemas que podem surgir, com o reconhecimento generalizado de capacidade plena, para a prática de atos da vida civil. De outro, entretanto, lança-se novos desafios para a doutrina brasileira, pois será preciso adequar à teoria das capacidades quando aplicada aos contratos. Ou seja, o sistema implantado não pode servir para desestabilizar as relações contratuais, que são de suma importância para a sociedade. Ainda, essas alterações não podem trazer insegurança jurídica na formação desses contratos, especialmente nos casos em que a deficiência cognitiva é de difícil ou impossível constatação, a priori, pela outra parte envolvida. ${ }^{6}$

\subsection{As peculiaridades da capacidade civil da pessoa com deficiência}

O EPD adotou um conceito abrangente de pessoa com deficiência para dizer que são aquelas que têm impedimentos de longo prazo de natureza física, mental, intelectual ou sensorial, as quais, em interação com diversas barreiras, podem obstruir sua participação plena e efetiva na sociedade em igualdade de condições com as demais pessoas (Artigo $1^{\circ}$ ). Porém, como já salientado, as deficiências físicas e sensoriais não interessam para os fins deste trabalho. De fato, o objetivo do artigo é tratar da capacidade civil da pessoa com deficiência cognitiva ${ }^{7}$ que pode afetar o contrato que venha a ser por ela celebrado.

A nova legislação consolida um modelo social, permeado pela necessidade da efetiva inclusão na sociedade, no qual a deficiência não é sinônimo de doença (modelo médico tradicional), mas barreira social a ser eliminada (PÉREZ BUENO; LORENZO GARCÍA, 2007). Sob esse espectro, a tutela jurídica não se justifica somente pelas limitações decorrentes de uma patologia, abarcando também a necessidade de uma estratégia social que propicie o pleno desenvolvimento do indivíduo. Logo, sendo o contrato uma forma de expressão do exercício do direito de igualdade e de liberdade no âmbito da sociedade, é correta a extensão da capacidade civil para a pessoa com deficiência, para que ela também possa firmar contratos como lhe aprouver.

O problema, portanto, reside na dificuldade da definição de algum nível de deficiência intelectual, pois existem deficiências cognitivas profundas, agudas e graves, moderadas e leves, as quais, por sua vez, podem exigir apoios intermitentes, limitados, extensos ou generalizados.

6 O Direito precisará adaptar-se para compreender essa nova realidade. Para ilustrar, existem basicamente quatro níveis de deficiência intelectual: profundo, agudo grave, moderado e leve. Os apoios também podem ser intermitentes, limitados, extensos e generalizados. Sugere-se consultar para maiores informações o trabalho de Erenice Carvalho e Diva Maciel (2003), publicado na revista Temas em Psicologia, sobre a American Association on Mental Retardation.

7 Existe alguma divergência a respeito do uso dessa terminologia. Entretanto, adota-se para o presente artigo uma observação lançada por Martha Nussbaum (2013, p. 120), que, se, de um lado não é capaz de resolver o problema, de outro fornece indicativos para compreender o sentido aqui proposto: “(...) na literatura sobre deficiência, 'impedimento' [impairment] é uma perda de função corporal normal; 'deficiência' [disability] é algo que você pode fazer em seu meio ambiente em função de uma lesão; handicap é a desvantagem competitiva resultante. No que se segue, tentarei levar em consideração essas distinções, apesar da linha entre lesão e deficiência ser difícil de estabelecer, particularmente quando o contexto social não é considerado fixo, mas aberto para debater. Como argumentarei, não podemos prevenir todas as deficiências, pois alguns impedimentos continuarão afetando a funcionalidade mesmo em um ambiente social justo. O que devemos fazer é prevenir o handicap com relação a direitos básicos." 
No percurso da formação da vontade contratual, partindo-se de uma premissa de boa-fé objetiva, tem-se um cenário muito delicado. Sob a perspectiva daquele que contrata com a pessoa (contratante) com deficiência, tem-se dois problemas iniciais: o primeiro refere-se à impossibilidade dele, segundo o quadro normativo atual, negar-se a celebrar o contrato por entender que o outro contratante possui alguma deficiência; já o segundo refere-se, de forma geral, que um dos contratantes (sem deficiência) não terá conhecimento científico necessário para definir se a deficiência cognitiva que envolve o outro contratante (com deficiência) é de natureza profunda, aguda grave, moderada ou leve. Some-se a isso a dinamicidade social que exige a formação de vontades de modo rápido e virtualizado, com grande redução das tratativas pessoais, que poderiam permitir a constatação de alguma deficiência cognitiva em um dos contratantes.

Esses problemas levam à rediscussão da capacidade civil no âmbito contratual. Até a entrada em vigor do EPD, eram considerados absolutamente incapazes (i) os menores de 16 (dezesseis) anos, (ii) os que, por enfermidade ou deficiência mental, não tivessem o necessário discernimento para a prática desses atos e (iii) os que, mesmo por causa transitória, não pudessem exprimir a sua vontade. Com a edição do Estatuto Pessoa com Deficiência (EPD), revogaram-se as duas últimas hipóteses e alterada a redação do caput, de tal sorte que, atualmente, somente os menores de 16 (dezesseis) são absolutamente incapazes. No plano da incapacidade relativa, remanescem os maiores de dezesseis e menores de dezoito anos, os ébrios habituais, os viciados em tóxico, e aqueles que, por causa transitória ou permanente, não puderem exprimir sua vontade e os pródigos.

O legislador conferiu-lhe capacidade civil plena, a partir da premissa de que a igualdade lhe fosse assegurada, com uma educação inclusiva, uma vida independente e a efetiva participação na comunidade. Ao mesmo tempo, admitiu - em caráter excepcional - o modelo jurídico da curatela, sem associá-la à incapacidade absoluta, porquanto preservada, tanto quanto possível, a autodeterminação para gerir as situações existenciais. E como fator de inserção, reconheceu a aptidão para celebrar contratos, uma vez que a maior parte dos atos da vida civil é manifestada dessa forma.

A premissa central está, então, bem delineada: a pessoa com deficiência cognitiva pode celebrar contratos possíveis de validação até prova em contrário. A partir deste ponto, o direito contratual precisará adaptar-se para compreender um mundo novo onde se inserem as deficiências cognitivas para, a partir dessa compreensão, delinear os novos contornos do regime das capacidades e até mesmo das invalidades no plano contratual.

O modelo atual para as deficiências mentais trabalha em cinco dimensões, conforme Erenice Carvalho e Diva Maciel (2003). A primeira dimensão é a das habilidades intelectuais, as quais são avaliadas de forma objetiva, no que se convencionou denominar de Coeficiente de Inteligência (QI), mas que perde a sua importância no diagnóstico por precisar ser avaliada com as demais dimensões. A segunda dimensão é a do comportamento adaptativo, ou seja, as habilidades que uma pessoa precisa deter para adaptar-se a vida quotidiana como, por exemplo: o domínio da linguagem e escrita com autonomia (habilidades conceituais); o senso de responsabilidade, autoestima, observância de normas e a ingenuidade (habilidades sociais); alimentar-se, preparar alimentos (habilidades práticas). Como terceira dimensão, tem-se a participação na vida comunitária, ou dimensão da participação e interação em papeis sociais, que visa identificar e avaliar a interação da pessoa com deficiência na comunidade em que se encontra inserida. A quarta dimensão é a da saúde e envolve as condições de saúde física e mental que podem influenciar o comportamento de uma pessoa. Finalmente, a quinta dimensão é a contextual (de habilidades sociais) - por sua vez, abarca as condições em que vive com a qualidade de vida -, inserida em um contexto familiar, social, cultural (p.e., neste ponto, as oportunidades educacionais, de trabalho, lazer).

Para o desenvolvimento deste trabalho, duas dimensões interessam em especial: dimensão do comportamento adaptativo e das habilidades sociais, pois se compreende que, no momento da celebração de um contrato, a pessoa precisa dominar a linguagem com autonomia para compreender a dimensão do conjunto de obrigações que está assumindo, além de ser necessário observar as normas legais. Caso a probabilidade de ser enganado na celebração de um contrato seja elevada, pode-se ter caso de anulabilidade, mas não de nulidade absoluta, conforme o novo regime legal em vigor (Artigos 171, inciso Il e 166, inciso I, do CC), já que a regra atual é de plena capacidade civil, sem a figura dos absolutamente incapazes (Art. $3^{\circ}, \mathrm{CC}$ ).

Isso interessa ao exercício da capacidade civil no âmbito contratual, pois se impõe a outra parte um ônus adicional relacionado a sua habilidade e preparo para identificar se aquela pessoa possui uma deficiência, que exija no momento da formação do contrato um nível de tratamento diferenciado, para permitir a exata compreensão do elemento obrigacional. Se de um lado tem-se o caso do ilícito, em que a parte contratante, percebendo a 
hipossuficiência cognitiva, se aproveita deliberadamente dessa condição, de outro é preciso considerar que a maior parte das pessoas age licitamente e poderá não verificar essa condição. Ou ainda, o que é pior, verificará, mas não poderá acusar essa condição sob pena de afrontar o próprio Estatuto Pessoa com Deficiência (EPD).

A própria alteração do EPD, que torna uma exceção a interdição da pessoa com deficiência, acaba por acrescentar um custo de transação adicional aos contratantes (Artigo 1.767 do CC). Em uma interlocução com o Art. $1^{\circ}$, do EPD, é preciso que a deficiência mental ou intelectual seja de longo prazo, o que deixa espaço para uma série de situações em que a deficiência é de curto prazo e que não demandará a interdição.

Portanto, a rigor, somente aquele que não puder exprimir sua vontade é que estará sujeito à curatela, nos limites a serem definidos pelo juiz, de acordo com suas potencialidades, o que pressupõe a realização prévia de entrevista, acompanhada por equipe multidisciplinar, para aferir o que poderá ou não fazer, sem a assistência de terceiros. Disso resulta que ela será considerada relativamente incapaz e assistida em determinados atos da vida civil, especificados judicialmente e, além de ter sua vontade e escolhas sempre respeitadas, a assistência de terceiros deve ser condizente com as particularidades de cada um e pelo menor período possível (FERRAZ, LEITE, LEITE, LEITE, 2012).

O EPD também criou o instituto jurídico consentâneo com a proposta de assegurar a capacidade jurídica plena da pessoa com deficiência para: a tomada de decisão apoiada, como alternativa à incapacidade relativa, assim disciplinada pelo Artigo 1.783-A do Código Civil (CC). Trata-se de instrumento por meio do qual a pessoa com deficiência indica pelo menos duas pessoas idôneas de sua confiança para lhe prestarem apoio no momento de deliberação sobre determinado ato da vida civil, mantendo-se a plena capacidade civil. Cabe ao magistrado, então, a definição dos limites do apoio, seus compromissos, o prazo de vigência e a exigência de que seja respeitada a vontade do apoiado.

Em resumo, em relação à pessoa com deficiência, existem três possibilidades:

I) não se enquadrar na hipótese de curatela, nem apresentar vulnerabilidade que justifique a indicação de terceiros para apoiá-la na tomada de decisão. Aqui, não há, a princípio, óbice à formalização de um contrato, pois se aplica na espécie a regra geral do Art. $6^{\circ}$ do EPD, combinada com o seu Art. 83, que reconhecem a capacidade legal plena da pessoa com deficiência, não sujeito à curatela e sem necessidade de auxílio de um apoiador nomeado. Nesta hipótese será caso de anulabilidade do contrato em que se demonstrar que a capacidade cognitiva reduzida foi utilizada em desfavor do contratante com deficiência, conforme Artigo 171, inciso II, do CC.

II) necessitar de curatela. Aqui, a pessoa com deficiência sob curatela pratica os atos da vida civil normalmente, com a assistência do curador, a qual é dispensada nas hipóteses relacionadas no Artigo $6^{\circ}$ do EPD. Nesta hipótese presume-se que o curador possui a capacidade cognitiva plena para tomar a decisão de contratar ou não, e que o fará em benefício dos interesses do contratante.

III) por sua vulnerabilidade, necessitar do apoio de terceiros para a tomada de decisão. Nesse caso, os apoiadores auxiliam a pessoa com deficiência na tomada de decisão sobre determinados atos, dentro dos limites estabelecidos no termo de apoio firmado por todos. Logo, para a celebração de contratos que se enquadram nos parâmetros definidos previamente, é necessário o respaldo da opinião daqueles; nas demais hipóteses, ele é livre para pactuar o que melhor lhe aprouver. Essas peculiaridades da capacidade civil precisam ser sopesadas em razão do novo regime inserido em nosso ordenamento pelo EPD.

\section{Os contratos celebrados por pessoas com deficiência na perspectiva da análise econômica do direito}

O contrato é um instituto eficiente para que haja a transformação do mundo real conforme o interesse dos seus contratantes, pois cria deveres e limita as possibilidades de ação dos sujeitos. Além disso, mais do que uma restrição ao comportamento, um contrato sugere comportamentos desejáveis (STAJN; ZYLBERSTAJN, 2005). Ocorre que, no mundo contratual tem-se um contexto em que os envolvidos possuem informações limitadas e dificuldade para processá-las adequadamente, o que influencia o processo decisório.

Como instrumento de análise do tema propõe-se o uso da Análise Econômica do Direito, partindo-se da constatação de que o estudo da capacidade contratual das pessoas com deficiência não é possível sem recorrer a ciências auxiliares (MACKAAY; ROUSSEAU, 2015), como a Sociologia, a Antropologia, a Psicologia e a Filosofia, as quais buscam analisar a ciência jurídica de uma forma que ela própria não poderia fazer. 
Para Miguel Reale, Direito e Economia são dois campos da vida humana que mantém uma interação constante, sem ser possível afirmar que há sobreposição de um sobre o outro, e sim um relacionamento dialético (REALE, 1988). Assim, a Análise Econômica do Direito tem por objetivo apresentar uma explicação de como o homem, observado sob o ponto de vista da Economia, reage às normas jurídicas. É uma teoria que não apenas avalia as consequências das escolhas humanas, mas também busca explicar o motivo dessas escolhas. Com essa confluência é possível desvendar e exprimir uma ordem subjacente ao direito, permitindo a melhor compreensão do cenário jurídico posto e, inclusive, de situações futuras (MACKAAY; ROUSSEAU, 2015), como os efeitos benéficos ou deletérios do EPD, ou, ainda, os incentivos para o cumprimento de uma obrigação assumida em contrato.

A Economia é acima de tudo uma ciência comportamental, pois a relação das pessoas com o mundo é explicada por elas agirem e serem governadas por regras que atingem diretamente a racionalidade humana (FRANK, 2014). Assim sendo, o comportamento humano perante o Direito depende do estabelecimento de critérios científicos que expliquem a forma com que ele convive em sociedade e como toma suas decisões.

Como marco teórico basilar, adota-se a obra seminal de Coase (1960), o artigo The Problem of Social Cost, que é reconhecido como o artigo científico mais citado no mundo da economia (POSNER, 1993) e é visto como o divisor de águas no estudo da Análise Econômica do Direito (RIBEIRO; GALESKI JUNIOR, 2009). Ele demonstrou que problemas entendidos como resultados naturais do sistema de mercado, como danos ambientais ou a terceiros, supostamente passíveis de solução unicamente por meio da regulação estatal, poderiam ser evitados através de arranjos privados de barganha, sem a necessidade de uma lei específica que, preteritamente, atribuia o direito a um ou outro envolvido (COASE, 1960).

Transpondo o problema para a capacidade do ato de contratar da pessoa com deficiência - a partir de uma limitação mental ou cognitiva -, tem-se que as informações podem ser ainda mais limitadas ou mais difíceis de serem processadas, o que não pode, em tese, afetar a relação contratual, pois, segundo o EPD, devido a igualdade material, não seria possível estabelecer uma distinção entre o contratante deficiente e o não deficiente, sob pena de macular o espírito da norma. Todavia, parece-nos que não é o caso de levar essa interpretação às últimas consequências.

Tendo um dos contratantes alguma deficiência, em certo nível, é preciso emprestar à capacidade uma modulação capaz de respeitar o desejo de contratar e de outro estabelecer os limites da obrigação contratual à luz da deficiência que possui o contratante, ou seja, é preciso "temperar" o sistema de modo a garantir algum nível de proteção ao deficiente que contrata ou é contratado.

Transpassando para a Análise Econômica do Direito, tem-se que ponderar os custos de transação envolvidos e a forma como serão internalizados. Portanto, segundo a teoria tradicional, a escolha entre o mecanismo de mercado ou o sistema internalizado depende da compreensão de que as transações são realizadas através de contratos (WILLIAMSON, 2012), os quais geram custos para a estrutura de governança. Assim, existem custos relativos ao desenho dos instrumentos contratuais, custos de monitorar o seu cumprimento e aqueles necessários para resolver os problemas que emergem a partir do seu descumprimento (STAJN; ZYLBERSTAJN, 2005). Da mesma forma, são três momentos específicos em que os custos de transação associados aos contratos podem surgir: a localização do parceiro comercial; a negociação entre eles e, por último, os custos para garantir o cumprimento do que foi pactuado (COOTER; ULLEN, 2010). Em resumo, é possível nominar os custos em três passos: (1) custos de busca e realização de um negócio, (2) custos de negociação e (3) custos do cumprimento do que foi negociado (RIBEIRO; GALESKI JUNIOR, 2009).

Na concepção da pessoa com deficiência, os custos de busca, negociação e cumprimento permanecem, ao menos aprioristicamente, iguais. Entretanto, a outra parte contratante (sem deficiência) terá um custo adicional, ou seja, a necessidade de aferir previamente que a capacidade mental ou cognitiva daquele que contratou não Ihe permitia dominar a linguagem com autonomia, para compreender a dimensão do conjunto de obrigações que estava assumindo.

Assim, há duas grandes categorias de custos de transação, apontadas por Williamson (1985), a dos custos ex ante e ex post. Os primeiros seriam aqueles para negociar e fixar as contrapartidas e salvaguardas do contrato; exigem o estudo do mercado, da legislação e da jurisprudência para adequação do negócio jurídico às expectativas dos contratantes. Já os custos ex post se materializam após a formalização do contrato, podendo existir com a ocorrência de eventos não previstos originalmente ou com os custos de se gerenciar eventuais disputas no decorrer das transações. 
Assim, as partes poderão optar por averiguar se a deficiência é anterior ou posterior a celebração do contrato. Ocorre que, atualmente, há uma larga opção por contratos de adesão ao invés das negociações individualizadas. Nesta hipótese, a confecção e utilização de contratos padrões diminuem os custos de se redigir novas cláusulas e condições, de modo que há apenas a adesão de uma parte a termos pré-estabelecidos por outra. De outro lado, a partir do EPD, essa opção também permite que se aplique a regra da melhor interpretação em favor do aderente, com uma nova categorização, ou seja, o contratante em geral é vulnerável, mas o contratante com deficiência mental ou cognitiva é hipervulnerável. A utilização de instrumentos idênticos e em larga escala redunda na inadequação das cláusulas contratuais às peculiaridades dos contratantes e objetos contratados e, por isso, gera custos ex post que precisam ser considerados no contrato. Contudo, apesar das possíveis externalidades negativas, a utilização de um único contrato em operações em massa dilui o custo de se redigir um bom instrumento contratual individualmente para cada transação.

Essa insuficiência de informações não constitui um problema insolúvel, pois ou o contrato sobrevive à incompletude informativa bilateral e à assimetria informativa, ou não subsiste, a menos que seja resgatado por uma iniciativa de integração vertical (ARAÚJO, 2014). Desse modo, converte-se em um peculiar custo de transação. De qualquer sorte, a assimetria informativa é um dos fatores que impede a verificação do mundo ideal coesiano.

O contrato é um acordo bilateral de conduta, com coordenação, e serve para assegurar o cumprimento do Direito (MACKAAY; ROUSSEAU, 2015). Se o equilíbrio for parcial, estar-se-á diante de um ajuste incompleto. Na hipótese de contrato celebrado por pessoa com deficiência mental ou cognitiva, o risco de não existir uma situação de equilíbrio é potencializado, na medida em que a distorção informativa é agravada e trabalha contra ela. Mesmo o equilíbrio parcial é questionável, porque o caso concreto pode envolver uma hipervulnerabilidade que favoreça em demasia a outra parte do contrato. ${ }^{8}$

Isso não leva imediatamente a anulabilidade ou nulidade do contrato. Todavia, há necessidade de adotar um novo parâmetro de equilíbrio visando à manutenção do contrato. Como regra, o Código Civil sustenta a necessidade da conservação do contrato, tanto que em seu Artigo 479 permite a modificação equitativa das condições do contrato, um corolário do Artigo 421 que trata da funcionalização social do contrato ${ }^{9}$, com o fortalecimento do princípio da conservação dos contratos, como é trabalhado em vários enunciados das Jornadas de Direito Civil do Conselho da Justiça Federal, como os Enunciados nº 22, 367 e 149.

Nessa mesma linha, oferece-se como solução ao problema da capacidade contratual da pessoa com deficiência instrumentos já existentes em nosso ordenamento jurídico, o que facilita a aplicação, mesmo que seja necessária alguma adaptação, como nos Artigos 138 e 157 do Código Civil. O primeiro artigo trata da anulabilidade por erro substancial e que remete ao conceito de pessoa de diligência normal. Em se tratando de pessoa com deficiência, é preciso avaliar se a declaração de vontade emanada é compatível com a de uma pessoa de diligência normal. Se a resposta for afirmativa, não há por que falar em erro substancial, ainda que a pessoa possua uma deficiência mental ou cognitiva. O Artigo 157, por sua vez, é utilizado sob a perspectiva da inexperiência: se uma pessoa com deficiência celebra um contrato, é preciso avaliar se a inexperiência envolvida é extraordinária ou normal, ou seja, comum ou não a qualquer tipo de pessoa, independentemente da capacidade cognitiva que possua.

Sob a perspectiva da Análise Econômica do Direito, é possível neste ponto invocar um dos seus desdobramentos conhecido por Behavioral Law and Economics, segundo a qual o agente age racionalmente e desenvolve uma conduta deliberadamente cingida a razões irrefutadas. Com efeito, a Teoria Comportamentalista da Decisão incide em uma análise particular da capacidade limitada em que as pessoas têm de apreender e processar as informações, as distorções que isso gera e os atalhos heurísticos que isso determina (MACKAAY; ROUSSEAU, 2015). Extraída de estudos mais recentes sobre o comportamento humano, as behaviors utilizam elementos da Psicologia, da Economia e do Direito, a partir da constatação de que a racionalidade é limitada por uma série de vieses ("desvios") e heurísticas ${ }^{10}$.

8 Essa premissa tem orientado o direito contratual moderno. Assim, destacam-se os Enunciados 23 e 167, das Jornadas de Direito Civil do Conselho da Justiça Federal, os quais atenuam a autonomia contratual e admitem uma nova teoria geral dos contratos. Embora não mencionem a pessoa contratante com deficiência, sustenta-se neste ponto a necessidade de adaptação da teoria geral dos contratos ao EPD, o que seria mais um passo nessa mudança.

9 Também é possível nominar outros artigos que possuem o mesmo espírito: Artigos 317, 478, 480, 157, 421, 422 do Código Civil, os quais, de diferentes modos, invocam o princípio da conservação da empresa.

10 A respeito disso, recomenda-se a leitura do trabalho de Christine Jolls, Cass Sunstein e Richard Thaler "A Behavioral Approach to Law and Economics", publicado em 1998. 
As pessoas com deficiência também possuem vieses e heurísticas que podem ser verificados e avaliados, segundo padrões de racionalidade e escolha limitada. Os modelos de análise econômica devem incluir variáveis psicológicas, recorrendo, por vezes, a noções jurídicas e econômicas, uma vez que as concepções sobre a racionalidade humana interferem nos resultados da atividade normativa.

Há, então, uma racionalidade limitada da pessoa com deficiência que precisa também ser observada. Por exemplo, pessoas com alguns tipos de autismo possuem uma memória excelente e uma capacidade de encontrar padrões, o que em tese pode ajudar na celebração de um contrato, todavia, é preciso considerar aspectos de coordenação mental que podem Ihes faltar para esse mesmo ato ${ }^{11}$. De outro lado, há uma crítica a respeito da Lei no 12.764/2012, que tratou dos Direitos da Pessoa com Espectro Autista, pois esta não apresentou distinção entre os diversos níveis de autismo, tornando todos que recebem esse diagnóstico simplesmente como pessoas deficientes, o que demonstra que o tema é controverso e somente torna mais necessário promover a discussão no campo da capacidade contratual (SALGADO, 2017).

Este parece ser o problema central do estudo da capacidade contratual da pessoa com deficiência: a dificuldade em definir o que é uma deficiência capaz de comprometer a vontade manifestada no contrato. Cumpre destacar que racionalidade limitada "não é a ponderação minuciosa, escrupulosa, articulada de todos os custos e benefícios associados à totalidade de opções que o horizonte cognitivo possa abarcar - mas apenas uma resposta diferenciada, e explicável, a estímulos variáveis..." (ARAÚJO, 2014, p. 28-29), sendo predominantemente procedimental e não finalística.

Na visão da Análise Econômica do Direito, os custos e benefícios financeiros esperados são comparados pelas partes contratantes entre diferentes e alternativos termos de um contrato e baseiam-se nas preferências que maximizam as suas utilidades. De acordo com os behavioristas, os indivíduos, em virtude de sua racionalidade e poder de escolha limitados, substituem a exigência do ótimo pelo suficiente, já que não ponderam os custos implícitos nas decisões (SANTOLIM, 2015).

Ocorre que, na perspectiva da pessoa com deficiência não é possível admitir uma racionalidade limitada nos moldes prescritos pela Economia. Se para uma pessoa sem deficiência a racionalidade é relativa e incapaz de transcender a simples ponderação dos custos implícitos, por certo que para a pessoa com deficiência mental ou cognitiva essa distância é ainda maior. Portanto, a perspectiva jurídica precisa considerar essa diferença na análise da capacidade contratual da pessoa com deficiência.

Na perspectiva do EPD, a revogação do sistema protetivo tradicional leva ao agravamento dos riscos para os contratantes, pois, além das situações normais de troca de informações, uma das partes deverá considerar que a outra possui algum nível de limitação cognitiva que poderá impactar a manifestação de vontade no ato da contratação, transferindo, em boa medida, o custo de transação de uma fase ex ante, para uma verificação ex post mais gravosa e onerosa. Para exemplificar, cite-se o contrato de consumo, em que há a vulnerabilidade inerente à hipossuficiência de um dos contratantes (o consumidor), à qual se acresce a decorrente da própria condição cognitiva do agente econômico, criando um sistema de hipervulnerabilidade contratual.

O tema não é propriamente novo na doutrina nacional, embora mantenha-se pouco desenvolvido. Neste ponto, a doutrina tem centrado seus esforços nos contratos de consumo, salientando a necessidade de uma diferenciação que não fique limitada apenas entre o consumidor e o fornecedor, mas que também abranja uma distinção entre os próprios consumidores, pois se trata de reconhecer a existência de um novo paradigma na teoria contratual. Com efeito, a proteção dos hipervulneráveis como pessoas com deficiência, idosos, crianças e adolescentes possui expressa previsão constitucional, enquanto outras características que também potencializam a vulnerabilidade, como analfabetismo, condição social e saúde acabam ficando de lado (ROSA; BERNARDES; FÉLIX, 2017), cabendo ao intérprete a análise pormenorizada dessas características.

Dentro dessa nova perspectiva, é preciso avaliar um conjunto de vulnerabilidades. Há a vulnerabilidade técnica - pois pode ocorrer do contratante com deficiência não dispor de um conhecimento específico capaz de

\footnotetext{
11 Para demonstrar a dificuldade para estabelecer um padrão comum para o autismo capaz de impactar sobre a capacidade contratual, leia-se: "Contemporaneamente, presenciamos as mais diversas formas de sintomas, que vão desde um comprometimento severo no desenvolvimento (fala ausente, grande dificuldade na interação, mesmo com familiares, hiperatividade, auto e hetero agressividade, etc.), até casos considerados mais 'leves' (caracterizados por dificuldades na comunicação e interação social, porém que demonstram afeto às pessoas mais próximas, área cognitiva preservada, etc.), o que determina grande dificuldade na elaboração do diagnóstico." (MARTINS; MONTEIRO, 2017, p. 215-224).
} 
orientar-Ihe a tomada de decisão -; a vulnerabilidade jurídica - pois a pessoa com deficiência pode ter dificuldade para avaliar quais os seus direitos e deveres na relação contratual -; a vulnerabilidade econômica - fruto da disparidade financeira entre as partes envolvidas; $-e$, finalmente, a vulnerabilidade fática - que é o desconhecimento do contrato que está sendo celebrado. Acresce-se, à pessoa com deficiência, uma série de outras vulnerabilidades particulares e multifacetadas em função da deficiência específica que nutrem. Assim, uma pessoa com autismo não submetida a qualquer regime de proteção terá uma vulnerabilidade específica a depender do contrato; um idoso que começa a manifestar o Mal de Alzheimer possui outro tipo de vulnerabilidade.

Interessante notar, então, que o regime de proteção do Código Civil atualmente é inferior, instrumentalmente, em relação ao regime do Código de Defesa do Consumidor (CDC), o que é um alento, pois permite à pessoa com deficiência refugiar-se nessa categoria jurídica: a de consumidor com deficiência mental ou cognitiva. De modo diferente, no Canadá adota-se neste ponto a visão de um paternalismo suave, que pode ser aplicado nos casos em que a pessoa contratante tem discernimento reduzido e a sanção é a nulidade dos atos que não foram assistidos por pais, tutor ou curador. Esse mecanismo, entretanto, é acionado somente a pedido da pessoa protegida, e apenas se houver prejuízo, conforme dispõe o Código de Québec (Mackaay e Rousseau, 2015)

Comparativamente, no Brasil, a edição do Estatuto da Pessoa com Deficiência (EPD) rompeu o sistema de proteção e lançou a pessoa com deficiência para o regime geral de proteções para os contratantes, que não considera distinções cognitivas. Por isso, socorrer-se com o CDC é uma saída viável a partir da noção de hipervulnerabilidade, bem como do instituto da lesão, que remete à noção de inexperiência e que também surge como um sistema de proteção minimamente satisfatório para relações contratuais onde haja uma pessoa com deficiência em um dos polos.

Para o Código Francês, a rescisão do contrato por lesão não é admitida, se resultar de evento casual e imprevisto, regra que tem por objetivo punir o oportunismo, e não simplesmente refazer o ajuste. Na teoria dos contratos, desapegada de uma racionalidade estrita, mas sem incorrer em irracionalidade, a compreensão dos diversos mecanismos que os agentes econômicos desenvolvem permite identificar as formas mais adequadas de estruturação dos ajustes e de monitoramento das condutas das partes, além de alternativas de implementação das cláusulas contratuais.

Com fundamento nos vetores orientadores da autonomia da vontade - a liberdade contratual, o consensualismo, a força obrigatória do contrato e o efeito relativo do contrato -, é lícito afirmar que a negociação e a pactuação do ajuste devem ser concluídas, se os interessados previrem que lhes serão favoráveis, caso inexistam nulidades. Isso porque qualquer um é livre para decidir contratar, definir o conteúdo das cláusulas que lhe convenham e escolher a outra parte contratante (MACKAAY; ROUSSEAU, 2015). No caso do EPD, essa liberdade para decidir contratar é estendida, sem ressalvas concretas, mas apenas gerais, às pessoas com deficiência mental, o que pode, inclusive, prejudicá-las, quando Ihes faltar discernimento suficiente para compreender e avaliar a extensão das obrigações e responsabilidades assumidas e o efetivo proveito econômico alcançável com a avença.

A liberdade contratual é manifestada na escolha dos seus parceiros, na estipulação e na moldagem do clausulado (ARAÚJO, 2014). Compreende, ainda, a possibilidade de não contratar e o direito de rejeitar potenciais contratantes, cláusula ou qualquer solução coordenadora ou disciplinadora. Com efeito, se partes estão vinculadas contratualmente, ficam ambas obrigadas a executar o que foi acordado, tendo em vista o princípio da força obrigatória do contrato, também denominada pacta sunt servanda, que confere segurança às relações jurídicas em geral. $\mathrm{Na}$ recusa de contratação com determinado interessado, a questão torna-se especialmente delicada, pois a negativa poderá vir a ser interpretada como discriminação.

O cerceamento dessa liberdade ou a ausência de capacidade plena de quaisquer dos contratantes (p.ex., da pessoa com deficiência) gera a invalidação do contrato, produzindo efeitos negativos - não só aos interessados como para toda a coletividade -, na medida em que frustra a concretização de uma operação econômica engendrada originariamente pelas partes. Em se tratando de pessoa com deficiência, não há a certeza quanto aos efeitos concretos de eventual decretação de nulidade, que é relativa.

O Direito não é indiferente à organização social, porquanto fenômeno social condicionante da realidade, mas na parte que trata da capacidade civil contratual é preciso reconhecer uma nova categoria jurídica que é a das pessoas com deficiência, o que leva a necessidade de desafiar a teoria tradicional dos contratos. 


\subsection{Os reflexos econômicos da invalidação do contrato}

Depreendendo-se das normas previstas no EPD que, seguindo uma tendência mundial, o legislador pátrio promoveu uma ampliação da autonomia das pessoas com deficiência - inclusive as acometidas por doenças mentais e cognitivas -, e afastou a sua condição de absolutamente incapaz, reservando o regime de curatela para situações excepcionais - exclusivamente em relação a atos relacionados a direitos patrimoniais e negociais, que excluem o direito ao próprio corpo, à sexualidade, ao matrimônio, à privacidade, à educação, à saúde, ao trabalho e ao voto. Além disso, cabe ao juiz explicitar as razões e motivações para a sua definição, preservando os interesses do curatelado.

Desse modo, criaram-se dois sistemas para as pessoas com deficiência: (a) uma regra geral, que é o reconhecimento da plena capacidade; (b) e uma regra especial, reservada para situações excepcionais, em que haverá algum tipo de controle prévio dos atos (curatela ou decisão apoiada). Portanto, as pessoas com discernimento reduzido ou desenvolvimento mental incompleto que puderem manifestar a sua vontade poderão praticar atos da vida civil, uma vez que não subsiste a presunção de relativa incapacidade. Dessa forma, as regras estabelecidas no EPD devem ser respeitadas, a fim de se evitar nulidades que gerem a frustração de uma operação contratual com reflexos diretos na Economia. A parte oposta do contrato não pode ser prejudicada se não sabia da incapacidade e não a percebeu no momento da celebração.

Conforme sustenta Araújo (2014), os contratos são as moléculas componentes do próprio mercado, a sua microestrutura. Por essa razão, sempre que possível deve ser reconhecida a validade do contrato, buscando evitar a sua anulação, sob pena de gerar impactos negativos no mercado. Essa linha é adotada pelo Código Civil brasileiro que, no seu Artigo 421, ao funcionalizar o contrato, previu que a regra não está na sua rescisão, mas na modificação equitativa das suas condições, consubstanciando o princípio da conservação do contrato, de modo a assegurar trocas úteis e justas. Portanto, mesmo que se considere a hipervulnerabilidade e a possível incidência das regras consumeristas para adequar a categoria jurídica, é possível também invocar a proteção do princípio da conservação do contrato de forma a tornar a troca adequada para os contratantes ainda que um deles seja deficiente no conceito jurídico da expressão.

Uma pessoa sem deficiência também pode fazer más escolhas ao celebrar um contrato, recorrendo a soluções contratuais munidas de informação limitada e de uma crença que desconhecem, porém também podem rever à medida que seu conhecimento vai se ampliando (ARAÚJO, 2014). Não há por que não pensar da mesma forma para relações contratuais envolvendo pessoas com deficiência. Assim, não é o fato de a pessoa contratante ter deficiência que leva à relativização do que foi contratado. Tal como qualquer pessoa, o deficiente também possui racionalidade limitada que varia conforme uma série de fatores definidos pela própria deficiência.

AAnálise Econômica do Direito, a partir da corrente behaviorista, somente vem corroborar com a constatação de que todos os indivíduos possuem uma racionalidade limitada e que os contratos são, geralmente, incompletos. Assim, mesmo uma pessoa com deficiência pode vir a trabalhar em um ambiente de limitação da racionalidade que lhe é própria, podendo ser maior ou menor a partir da amplitude da sua deficiência. Portanto, ainda que o novo sistema tenha enfraquecido o regime de garantias anteriormente construído pela doutrina jurídica, um pouco de esforço argumentativo permite concluir que é possível e necessário adaptar as categorias jurídicas contratuais a essa nova realidade que o EPD trouxe para o ordenamento jurídico, recorrendo-se a institutos já previstos. É preciso, portanto, apenas promover a mudança do ângulo de abordagem da capacidade civil enquanto categoria jurídica essencial à formação dos contratos para abarcar uma nova realidade, que é aquela proporcionada pela inclusão da pessoa com deficiência no ambiente democrático e dinâmico das relações contratuais.

Nessa perspectiva, os contratantes necessitam manter o negócio jurídico, mesmo que alguma das partes seja uma pessoa com deficiência. Em caso de conflito contratual que venha a ser levado aos tribunais, os magistrados devem valer-se das novas regras sobre incapacidades, estabelecidas pelo EPD, para, na medida do possível, conservar o contrato da forma que foi assinado.

Nos ensinamentos de Nestor Duarte (2012), se o agente contratante se acha em estado de regressão, sendo impossível ou dificultoso comprovar-se a deficiência mental, o negócio deve ser preservado, para a proteção da boa-fé do outro contratante. Já se a insanidade é notória, ou conhecida do outro contratante (sem deficiência), este contrato será anulado. Isso, porém, não afasta outra premissa importante, definida por Silvio Rodrigues (2008), que afirma que cabe ao ordenamento jurídico proteger o terceiro de boa-fé, pois esse valor seria mais importante que o interesse do incapaz. 
Assim, toda vez que é declarada a nulidade de um contrato, há a frustração de uma operação econômica, o que gera um custo social e econômico, além de insegurança jurídica. Pressupõem, portanto, que, se os contratantes estiverem de boa-fé, o negócio jurídico é válido, e que para haver anulação é indispensável a prova de que a doença era incapacitante sob a ótica cognitiva na época em que foi celebrado, pois caso contrário, o impacto econômico da nulidade do contrato seria enorme e com sérios transtornos para a sociedade. Essa premissa se amolda ao que estabelece o Artigo 421 do Código Civil que, por sua vez, também calha com o Artigo 157 do mesmo diploma.

O direito contratual e os tribunais podem reduzir os custos de transação da cooperação, ao interpretar as promessas e articular condições eficientes, corrigindo falhas do mercado que minimizam a ameaça ao comportamento oportunista (COOTER; ULLEN, 2010). Ocorre que, ao editar o EPD, o legislador acabou por gerar custos de transação adicionais, na medida em que retirou o sistema de proteção anteriormente existente, sem prever um substituto, deixando à mercê de circunstâncias gravosas não somente a pessoa com deficiência como, também, a outra parte da relação contratual.

Além disso, em relação à pessoa com deficiência que não possui curador, nem se vale de apoio de terceiros para a tomada de decisão, o legislador transferiu o momento de verificação dos custos de transação de ex ante para ex post, partindo do pressuposto da necessidade de conferir igualdade de condições aos contratantes. Entre o custo de verificar a capacidade civil contratual, em situação ex post, e negar a possibilidade da contratação, enquanto expressão da autonomia da vontade da pessoa com deficiência, preferiu o legislador ficar com a primeira, embora isso traga preocupações para o direito contratual. Destarte a isso, foi possível verificar que o próprio Código Civil fornece um conjunto de soluções normativas apropriadas para preservar o contrato na medida do possível, sem macular os interesses das partes envolvidas, ainda que uma delas seja deficiente.

Não se perca de vista que o sistema anterior ao EPD não visava a discriminação da pessoa com deficiência mental, mas sim a promoção de sua proteção em um momento ex ante, contribuindo para reduzir tentativas de ludibriá-la e enganá-la. Com a nova normativa legal, valorizaram-se aspectos subjetivos relacionados à dignidade da pessoa humana em detrimento de aspectos objetivos que emanam da celebração do contrato, deslocando o controle de sua validade da fase anterior para a posterior, ou seja, quando já celebrado e em fase de cumprimento. Consequentemente, os custos de transação são, na maioria das vezes, maiores, pois eventual correção dar-se-á quando o contrato já estiver produzindo seus efeitos. Se, para pessoas com plena capacidade, não raras vezes, é difícil compreender a extensão e os efeitos de alguns contratos, que dirá para uma pessoa com alguma deficiência cognitiva.

Pensando nisso, aparentemente, o legislador olvidou que há diferença entre consentir e discernir e, em algumas modalidades contratuais, a existência ou não de capacidade plena apresenta-se como desnecessária, pois se compreende que os efeitos jurídicos já estão prefigurados na legislação ou, então, apresentam-se como idênticos para todo e qualquer contratante. Um exemplo: qualquer pessoa que embarca em um ônibus do transporte coletivo público estará automaticamente celebrando um contrato de transporte, tenha ela ou não capacidade cognitiva plena ou limitada. Entretanto, existem contratos em que os efeitos jurídicos não estão prefigurados e podem ser celebrados na forma particular, ou seja, sem o crivo de um notário público ou a prévia participação do legislador na definição do conteúdo do ajuste. Também haverá casos em que não existirá curador ou terceiro apoiador. Assim, e, em relação a tais contratos, vigorará, por força do EPD, a regra da capacidade plena de qualquer agente econômico, seja ele ou não pessoa com deficiência, além do controle de validade se dar por ex post.

De modo geral, o EPD atuou na fase do consentimento, permitindo que pessoas com deficiência mental ou cognitiva possam celebrar contratos, mas sem afirmar, no entanto, que estas tenham o discernimento necessário para compreenderem a extensão das obrigações e responsabilidades que assumem. Além disso, compreendese que a solução preconizada - designação de curador pelo juiz - nem sempre será buscada a tempo e modo desejados. É nesse ponto, portanto, que reside o problema, pois, doravante, somente por provocação judicial é que o problema poderá ser resolvido, cabendo ao Poder Judiciário corrigir os rumos da vontade emanada pela pessoa com deficiência mental atendo-se ao princípio da conservação do contrato.

\section{Conclusão}

Os requisitos subjetivos para existência e validade dos contratos deixam clara a relevância da capacidade civil plena dos agentes para a promoção de trocas econômicas. Com o advento do EPD, foi alterada a divisão 
de incapacidade relativa e absoluta (está restrita aos menores de 16 anos). Essa alteração teve como objetivo a garantia da dignidade da pessoa com deficiência, que passa a participar efetivamente da vida em sociedade sem ter seus atos limitados por lei.

A partir dos estudos da Análise Econômica do Direito, promove-se a análise dos custos de transação envolvidos nos contratos, e percebe-se que essa alteração legislativa acabou por transferir custos do ex ante para o ex post. Com isso, os custos envolvidos na redução da assimetria entre as partes deixam de ocorrer antes da celebração do contrato e passam a ocorrer durante a sua execução. Essa realidade acaba por ameaçar a segurança jurídica envolvida na celebração de contratos, já que os contratos firmados com pessoas com deficiência cognitiva serão levados ao Poder Judiciário para que eventuais prejuízos decorrentes dessa característica sejam mitigados. Cabe então ao Poder Judiciário aplicar princípios como a presunção da boa-fé, da autonomia das partes e da conservação do contrato, para evitar que os efeitos de eventual contrato realizado com pessoa com capacidade reduzida afetem o sistema econômico, extrapolando a relação entre contratantes.

Além disso, com a mudança no ordenamento, renunciou-se aos mecanismos de proteção dos deficientes hipossuficientes então previstos em lei, sem que fosse previsto mecanismo substitutivo igualmente abrangente. Trata-se então de entrave na liberdade e igualdade do deficiente (objetivadas pelo EPD), ou seja, o risco de haver prejuízo ao hipossuficiente (mesmo que não haja conhecimento dessa circunstância) pode acabar incentivando agentes econômicos a não efetivar processos de contratação com pessoas com deficiência, o que seria o oposto ao desejado pela legislação.

Para superar as dificuldades apresentadas, sugere-se a utilização de mecanismos já presentes no ordenamento jurídico brasileiro como, por exemplo: a anulabilidade por erro substancial (Art. 138 do Código Civil) e o instrumento da lesão, em especial sob a perspectiva da inexperiência (Art. 157 do Código Civil). Em ambos os casos, entretanto, depende-se de revisão, via Poder Judiciário, para que a pessoa com deficiência seja protegida, mesmo que sua vulnerabilidade seja reconhecida pelo ordenamento. Desse modo, essa vulnerabilidade passa a ser levada em consideração apenas após a ocorrência (mesmo que parcial) dos efeitos negativos do contrato, enquanto o ideal seria a tutela em todas as fases da negociação.

\section{Referências}

ARAÚJO, Fernando. Introdução à economia. 3. ed. Lisboa: Almedina, 2014.

BRASIL. Decreto Legislativo $\mathrm{n}^{\circ}$ 186, de 09 de julho de 2008. Aprova o texto da Convenção sobre os Direitos das Pessoas com Deficiência e de seu Protocolo Facultativo, assinados em Nova lorque, em 30 de março de 2007. Brasília, DF: Senado Federal, [2021]. Disponível em: http://www.planalto.gov.br/ccivil_03/congresso/dlg/ dlg-186-2008.htm. Acesso em: 16 abr. 2021.

BRASIL. Decreto ${ }^{\circ}$ 6.949, de 25 de agosto de 2009. Promulga a Convenção Internacional sobre os Direitos das Pessoas com Deficiência e seu Protocolo Facultativo, assinados em Nova York, em 30 de março de 2007. Brasília, DF: Presidência da República, [2021]. Disponível em: http://www.planalto.gov.br/ccivil_03/_ato20072010/20s09/decreto/d6949.htm. Acesso em: 16 abr. 2021.

BRASIL. Lei $\mathbf{n}^{\circ}$ 10.406, de 10 de janeiro de 2002. Institui o Código Civil. Brasília, DF: Presidência da República, [2021]. Disponível em: http://www.planalto.gov.br/ccivil_03/leis/2002/l10406compilada.htm. Acesso em: 16 abr. 2021.

BRASIL. Lei $\mathbf{n}^{\circ}$ 12.764, de 27 de dezembro de 2012. Institui a Política Nacional de Proteção dos Direitos da Pessoa com Transtorno do Espectro Autista; e altera o $\S 3^{\circ}$ do art. 98 da Lei $n^{\circ} 8.112$, de 11 de dezembro de 1990. Brasília, DF: Presidência da República, [2021]. Disponível em: http://www.planalto.gov.br/ccivil_03/_ ato2011-2014/2012/lei//12764.htm. Acesso em: 16 abr. 2021.

BRASIL. Lei no 13.146, de 06 de julho de 2015. Institui a Lei Brasileira de Inclusão da Pessoa com Deficiência (Estatuto da Pessoa com Deficiência). Brasília, DF: Presidência da República, [2021]. Disponível em: http:// www.planalto.gov.br/ccivil_03/_Ato2015-2018/2015/Lei/L13146.htm. Acesso em: 16 abr. 2021. 
BRASIL. Secretaria Nacional de Promoção dos Direitos da Pessoa com Deficiência. Cartilha do Censo 2010: pessoas com deficiência. Brasília, DF: SDH-PR/SNPD, 2012. Disponível em: https://bibliotecadigital.mdh.gov.br/ jspui/handle/192/754. Acesso em:16 abr. 2021.

CANADÁ. Civil Code of Québec. Québec: Éditeur Officiel du Québec, 2021. Disponível em: http://legisquebec. gouv.qc.ca/fr/showdoc/cs/ccq-1991. Acesso em: 16 abr. 2021.

CARVALHO, Erenice Natália Soares de; MACIEL, Diva Maria Moraes de Albuquerque. Nova concepção de deficiência mental segundo a American Association on Mental Retardation - AAMR: sistema 2002. Temas em Psicologia, Ribeirão Preto, v. 11, n. 2, p. 147-156, 2003. Disponível em: http://pepsic.bvsalud.org/scielo. php?script=sci_arttext\&pid=S1413-389X2003000200008\&lng=pt\&nrm=iso\&tlng=pt. Acesso em: 16 abr. 2021.

COASE, Ronald. The problem of social cost. The Journal of Law \& Economics, Chicago, v. 3, p. 1-44, out. 1960. Disponível em: https://www.law.uchicago.edu/files/file/coase-problem.pdf. Acesso em: 16 abr. 2021.

COOTER, Robert; ULLEN, Thomas. Direito e economia. Tradução: Luis Marcos Sander, Francisco Araújo da Costa. 5. ed. Porto Alegre: Bookman, 2010.

DUARTE, Nestor. Comentários à parte geral (artigos $1^{\circ}$ ao 232). In: PELUSO, Cezar (coord.). Código Civil comentado: doutrina e jurisprudência: Lei n. 10.406, de 10.01.2002: contém o Código Civil de 1916. 6. ed. rev. e atual. Barueri, SP: Manole, 2012. p. 15-178.

FARIA, Guiomar T. Estrella. Interpretação econômica do direito. Porto Alegre: Livraria do Advogado, 1994.

FERRAZ, Carolina Valença et al. Manual dos direitos da pessoa com deficiência. São Paulo: Saraiva, 2012.

FRANÇA. Code Civil. [Paris]: Legifrance, [2021]. Disponível em: https://www.legifrance.gouv.fr/codes/id/ LEGITEXT000006070721/. Acesso em: 16 abr. 2021.

FRANK, Robert H. Economics and behavior. New York: McGraw-Hill, 2014.

INSTITUTO BRASILEIRO DE GEOGRAFIA E ESTATÍSTICA. Nota Técnica 01/2018: releitura dos dados de pessoas com deficiência no Censo Demográfico 2010 à luz das recomendações do Grupo de Washington. [Brasília]: IBGE, 2018. Disponível em: https://ftp.ibge.gov.br/Censos/Censo_Demografico_2010/metodologia/ notas_tecnicas/nota_tecnica_2018_01_censo2010.pdf. Acesso em: 16 abr. 2021.

JOLLS, Christine; SUNSTEIN, Cass R.; THALER, Richard. A behavioral approach to law and economics.

Stanford Law Review, Stanford, v. 50, p. 1471-1550, maio 1988. Disponível em: http://www.law.harvard.edu/ programs/olin_center/papers/pdf/236.pdf. Acesso em: 16 abr. 2021.

LAKATOS, Eva Maria; MARCONI, Marina de Andrade. Fundamentos da metodologia científica. 5. ed. São Paulo: Atlas, 2003.

MARTINS, Alessandra Dilair Formagio; MONTEIRO, Maria Inês Bacellar. Alunos autistas: análise das possibilidades de interação social no contexto pedagógico. Psicologia Escolar e Educacional, São Paulo, v. 21, n. 2, p. 215-224, maio/ago. 2017. Disponível em: https://www.scielo.br/pdf/pee/v21n2/2175-3539pee-21-02-00215.pdf. Acesso em: 16 abr. 2021.

MACKAAY, Ejan; ROUSSEAU, Stéphane. Análise econômica do direito. Tradução: Rachel Szatajn. 2. ed. São Paulo: Atlas, 2015.

MIRANDA, Francisco Cavalcanti Pontes de. Tratado de direito privado: parte geral. 4. ed. São Paulo: Revista dos Tribunais, 1983. t. 1.

MONTEIRO, Washington de Barros. Curso de direito civil. São Paulo: Saraiva, 1974.

NORONHA, Fernando. O direito dos contratos e seus princípios fundamentais. São Paulo: Saraiva, 1994.

NUSSBAUM, Martha C. Fronteiras da justiça: deficiência, nacionalidade, pertencimento à espécie. Tradução: Susana de Castro. São Paulo: Editora WMF Martins Fontes, 2013. 
PÉREZ BUENO, Luis Cayo; LORENZO GARCÍA, Rafael. Los difusos limites de la discapacidad en el futuro: hacia un nuevo estatuto de la discapacidad. In: LOURENÇO, Rafael de; PÉREZ BUENO, Luiz Cavo (dir.). Tratado sobre discapacidad. Navarra: Editorial Aranzadi, SA, 2007. p. 1551-1566.

REALE, Miguel. Lições preliminares de direito. 16. ed. São Paulo: Saraiva, 1988.

RIBEIRO, Marcia Carla Pereira; GALESKI JUNIOR, Irineu. Teoria geral dos contratos: contratos empresariais e análise econômica. Rio de Janeiro: Elsevier, 2009.

POSNER, Richard. Nobel Laureate: Ronald Coase and methodology. The Journal of Economic Perspectives, Pittsburgh, v. 7, n. 4, p. 195-210, 1993. DOI: 10.1257/jep.7.4.195. Disponível em: http://www3.nccu.edu. tw/ hmlien/pfinance/pf1/readings/coase.pdf. Acesso em: 20 set. 2021.

RODRIGUES, Silvio. Direito civil: direito de família. 28. ed. São Paulo: Saraiva, 2008.

ROSA, Luiz Carlos Goiabeira; BERNARDES, Luana Ferreira; FÉLIX, Vinícius Cesar. O idoso como consumidor hipervulnerável na sociedade de consumo pós-moderna. Revista Jurídica da Presidência, Brasília, v. 18, n. 116, p. 533-558, out. 2016/jan. 2017.

SALGADO, Ana Clara Lopes. Capacidade civil dos portadores do transtorno do espectro autista: análise do conceito e dos mecanismos da capacidade civil perante os diversos tipos do transtorno psicológico. VirtuaJus, Belo Horizonte, v. 2, n. 3, p. 303-320, $2^{\circ}$ sem. 2017.

SANTOLIM, César Viterbo Matos. "Behavioral law and economics" e a teoria dos contratos. Revista Jurídica Luso-Brasileira, Lisboa, ano 1, n. 3, p. 407-430, 2015.

STAJN, Raquel; ZYLBERSTAJN, Décio (org.). Direito \& economia: análise econômica do direito e das organizações. Rio de Janeiro: Elsevier, 2005.

THEODORO JÚNIOR, Humberto. O contrato e sua função social. Rio de Janeiro: Forense, 2003.

WILLIAMSON, Oliver E. The economic institutions of capitalism. New York: The Free Press, 1985.

WILLIAMSON, Oliver E. As instituições econômicas do capitalismo: firmas, mercados, relações contratuais. São Paulo: Pezco Editora, 2012.

Recebido em: 08.07.2020

Aceite em: 01.09.2021 